\title{
FOTOGRAFÍA SUBJETIVA Y GRUPOS FOTOGRÁFICOS Fotoform, La Carpeta de los Diez y Afal
}

\author{
SUBJECTIVE PHOTOGRAPHY AND \\ PHOTOGRAPHIC GROUPS \\ Fotoform, La Carpeta de los Diez and Afal
}

\author{
JULIETA PESTARINO \\ julietapestarino@gmail.com \\ Dirección de Archivos de Arquitectura y Diseño Argentinos. Facultad de Arquitectura, Diseño y \\ Urbanismo. Universidad de Buenos Aires. Argentina \\ Recibido 9/5/2019 | Aceptado 11/8/2019
}

\section{Resumen}

Luego de la Segunda Guerra Mundial, comenzaron a formarse tanto en Europa como en Latinoamérica agrupaciones de fotógrafos que combinaron diversos grados de aportes de la fotografía humanista, desarrollada principalmente en Francia, en Italia y en Estados Unidos, con elementos de la fotografía subjetiva alemana. Muchos de estos grupos presentaron características y propósitos similares, en un contexto de época en el que la fotografía buscaba su constitución como disciplina artística con métodos y alcances específicos mediante la afirmación de su propio estatus autónomo. Este trabajo propone indagar las influencias del grupo alemán Fotoform y los preceptos de la fotografía subjetiva propuestos por Otto Steinert, sobre los grupos fotográficos Afal, de España, y La Carpeta de los Diez, de Argentina.

\section{Palabras clave}

Fotografía subjetiva; Fotoform; La Carpeta de los Diez; Afal

\section{Abstract}

After World War II, several photography groups started gathering both in Europe and in Latin America, bringing together elements from humanist photography, mainly developed in France, in Italy and in the United States, and from German subjective photography. Many of these groups had similar purposes and characteristics, within a time in which photography as art was seeking its autonomous status through specific methods and scope. This work explores the influence the German group Fotoform, and the precepts of subjective photography provided by Otto Steinert, had over the photography groups Afal from Spain and La Carpeta de los Diez from Argentina.

\section{Keywords}

Subjective photography; Fotoform; La Carpeta de los Diez; Afal

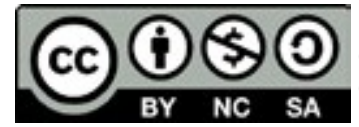


En los años inmediatamente posteriores a la Segunda Guerra Mundial, Europa asistió a un regreso de la fotografía como medio artístico y expresivo luego del oscuro período de guerra y de nazismo. En Alemania en particular, los años previos al estallido de la guerra se habían visto marcados por la corriente de la Nueva Objetividad (Neue Schlichkeit) ${ }^{1}$ junto a los aportes artísticos de vanguardia de la Bauhaus, con László Moholy-Nagy como uno de sus principales referentes. Sin embargo, este camino de experimentación y desarrollo expresivo al interior de la fotografía fue interrumpido por el ascenso del nazismo y el establecimiento de nuevos parámetros de apreciación del arte según lo que se dio a llamar como 'arte degenerado' (Entartete Kunst).

Al finalizar la guerra, Alemania comenzó un proceso de reconstrucción y restauración, en el cual también se inscribió la fotografía como expresión artística. En este contexto tuvo lugar en 1949 la creación de un grupo fotográfico llamado Fotoform, conformado en sus inicios por los alemanes Peter Keetman, Ludwig Windstosser, Wolfgang Reisewitz, Siegfried Lauterwasser, Toni Schneiders y Otto Steinert, su principal referente, a quienes más tarde se les sumaría Christer Christian, de Suecia, y Heinz Hajek-Halke, de Alemania. El grupo propuso una revalorización de las vanguardias de las décadas de 1920 y de 1930, las expresiones del Nuevo Objetivismo y las experiencias de la Bauhaus y la Nueva Visión, junto con un empleo más experimental de los recursos fotográficos con una mayor libertad creativa. El nombre del grupo, sugerido por Steinert, apuntaba hacia los experimentos fotográficos formales, obtenidos a través de marcos o puntos de vista inusuales, y subvertía aspectos técnicos como el enfoque y la exposición, o la manipulación de los procesos de laboratorio (Valentin, 2016, p. 12).

Los miembros de Fotoform buscaron realizar imágenes que expresaran una subjetividad privilegiada a través de recursos puramente fotográficos. Con el objetivo de lograr un medio expresivo específico con la fotografía y en ella, hicieron uso de diversos procedimientos técnicos como montajes, solarizaciones, fotogramas, múltiples y largas exposiciones, manipulaciones de la luz, encuadres radicales experimentales y altos contrastes, entre otros procedimientos desplegados tanto al momento de toma como en el posterior trabajo de laboratorio [Figura 1].

El grupo guiado por Steinert rápidamente comenzó a publicar y a exponer sus producciones haciendo circular sus fotografías por publicaciones alemanas e internacionales, así como en salones y en exposiciones de todo el mundo. En mayo de 1950 se realizó en Colonia la primera feria Photokina, concebida específicamente para la industria fotográfica, la cual abarcaba todos los aspectos de la fotografía profesional y amateur, y buscaba celebrar el renacimiento de la fotografía alemana después de la guerra. La feria albergó diversas

1 El término ‘Neue Sachlichkeit' (Nueva Objetividad) surgió en Alemania a mediados de la década de 1920, en relación con una escuela de pintura que fundamentaba la objetividad del estilo y el contenido, buscando un realismo basado en la crítica social. El término se extiendió posteriormente hacia otros medios expresivos, tomando como referentes principales en fotografía a Albert Renger-Patzsch y Karl Blossfeldt. La Nueva Objetividad fotográfica se enfoca esencialmente en los objetos como forma espacial pura, como estructura y materia (Guillemot, 2001, p. 453). 
exposiciones, entre ellas la primera muestra de Fotoform con 29 fotografías. En 1951 el grupo participó también de la segunda edición de Photokina y en 1953 mostró su trabajo por primera vez en Bélgica, en la ciudad de Charleroi, ${ }^{2}$ entre otras participaciones.
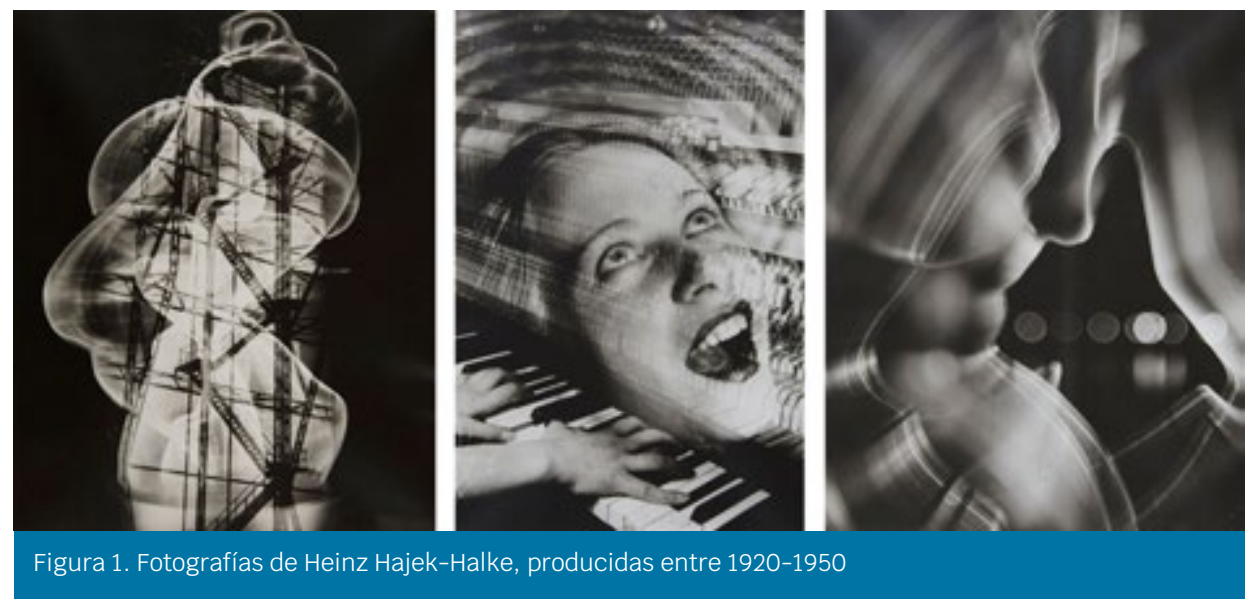

Las imágenes de Fotoform pueden incluirse, en muchos casos, dentro del movimiento abstraccionista que caracterizó en gran parte a la fotografía de la década del cincuenta. De hecho, en 1951 el Museo de Arte Moderno de Nueva York (MoMA) dio lugar a la exposición Abstraction in Photography [Abstracción en fotografía], organizada por Edward Steinchen. Lejos de conformarse como un movimiento acabado, la abstracción de esta exposición se podía encontrar en diferentes tipos de fotos (Baker, 2018) y fotógrafos de diversas tradiciones, reuniendo imágenes tanto de László Moholy-Nagy y de Man Ray como de Henri Cartier-Bresson. Sin bien participaron 103 autores de diversas nacionalidades, ningún miembro de Fotoform formó parte de la muestra. ${ }^{3}$

Paralelamente a la exposición del MoMA, Steinert organizó en 1951 la primera de una serie de tres exposiciones internacionales de lo que daría a llamar fotografía subjetiva (subjektive fotografie), la cual tuvo lugar en la Escuela de Arte y Artesanía de Saarbrücken en donde Steinert, médico devenido en fotógrafo, trabajaba como profesor (Gernsheim \& Gernshaw, 1965). La exposición reunió 725 fotografías de fotógrafos europeos y estadounidenses, seleccionadas especialmente por Steinert bajo sus criterios de fotografía subjetiva.

2 Un estudio puntual sobre la relación de Fotoform, Otto Steinert y la fotografía subjetiva especialmente con la fotografía en Bélgica se encuentra en el trabajo de Tamara Berghmans (2011) "The emergence of photography as an art form in Belgium, 1950-1965» [El surgimiento de la fotografía como una forma de arte en Bélgica, 1950-1965].

3 Un listado completo de todos los fotógrafos participantes en esta exposición puede ser consultado online en el sitio web del museo: https://www.moma.org/documents/moma_master-checklist_325775.pdf 


\begin{abstract}
La exposición pretendía demostrar que la fotografía estaba en sintonía con la modernidad en forma y contenido en todo el mundo. Cerrando la brecha entre las modernas vanguardias y la producción contemporánea del momento, Steinert incluyó obras de László Moholy-Nagy, Raoul Haussman y Herbert Bayer, emigrados que habían sido activos fotógrafos en Alemania antes de la guerra [...]. Su diseño interactuó hábilmente con el entorno arquitectónico único: las fotos se colgaron como pancartas en postes, se colocaron en postes suspendidos de techos altos, o en paneles en ángulo desde las paredes (Valentin, 2016, pp. 12-13).
\end{abstract}

El gran número de imágenes participantes y la descripción del montaje de fotos, que colgaban como pancartas, eran características de las exposiciones fotográficas de la época, herederas de la tradición de la «exposición fotográfica expandida» (Ribalta, 2009), basada en grandes exposiciones soviéticas y alemanas de las décadas del veinte y del treinta. ${ }^{4}$ Esta primera exposición de fotografía subjetiva fue acompañada por un catálogo con introducción de Steinert en el cual el autor afirma que, al mostrar una selección de «fuerzas creativas en la fotografía actual», la exposición intentó «arrojar luz sobre los esfuerzos de la fotografía contemporánea» (Valentin, 2016, p.12). ${ }^{5}$ En aquel texto, Steinert especificó también que el título fotografía subjetiva hacía referencia al «momento personal creativo del fotógrafo (en oposición a la fotografía "aplicada" que sirve a los fines cotidianos o documentales)», ${ }^{6}$ según lo cual la intervención del fotógrafo en la creación de la imagen final era un eje central para la selección de los autores y de las imágenes que se incluyeron. Esta primera exposición fue posteriormente exhibida en otras ciudades de Alemania y, tres años más tarde, en Nueva York, siendo la itinerancia un rasgo distintivo de la difusión de la fotografía subjetiva como así también de Fotoform.

Poco tiempo después, Steinert publicó el libro Fotografía subjetiva (1952) con textos en alemán y en inglés del propio Steinert, del historiador del arte Josef Adolf Schmoll y del fotógrafo e historiador del arte Franz Roh, en los cuales se establecían las bases teóricas de la fotografía subjetiva. En su artículo «Sobre las posibilidades creadoras de la fotografía» (1952) Steinert afirma que existen «etapas diversas de perfeccionamiento en el dominio de la creación fotográfica» que, según los «factores técnicos y subjetivos efectivos» podrían clasificarse como: a) la copia fotográfica tendente a la reproducción; b) la copia fotográfica tendente a la representación; c) la creación fotográfica tendente a la representación; y d) la creación fotográfica absoluta (Steinert, 1961, p.33). ${ }^{7}$ Estas etapas suponen una progresiva pérdida del referente fotografiado, ya que mientras que en la tercera etapa «el motivo no se toma por su valor intrínseco, sino que se eleva a

4 Para un estudio detallado de las exposiciones fotográficas expandidas y sus antecedentes ver Espacios fotográficos públicos. Exposiciones de propaganda, de Pressa a The Family of Man, 1928-1955 (2009) y Archivo universal. La condición del documento y la utopía fotográfica moderna (2008), ambos de Jorge Ribalta.

5 «Creative forces in present-day photography [...] shed light on the efforts of contemporary photography» (Valentin, 2016, p.12). Traducción de la autora.

6 «The personal creative moment of the photographer (as opposed to "applied" photography serving every day or documentary purposes)» (Valentin, 2016, p.12). Traducción de la autora.

7 El artículo "Sobre las posibilidades creadoras de la fotografía» de Otto Steinert fue publicado en español en el revista AFAL №32 en 1961, de allí se obtuvo la presente cita. 
la categoría de base para la creación» (Steinert, 1961, p.33), en la cuarta los objetos no se reproducen en absoluto. Mediante esta clasificación Steinert explica que considera fotografías propiamente subjetivas a aquellas que podrían incluirse en la tercera y cuarta etapas, es decir, «imágenes que no pueden agruparse bajo el estereotipo habitual de categorías de concepción fotográfica» (Valentin, 2016, p. 15). De esta manera, el fotógrafo mismo es el verdadero tema de las fotografías subjetivas, a menudo fuertemente formales. Cualquier experimentación con técnicas puramente fotográficas es utilizada al servicio de la expresión personal, en búsqueda de una supresión de la dimensión icónica de la fotografía en pos de una abstracción completa de la imagen (Berghmans, 2011).
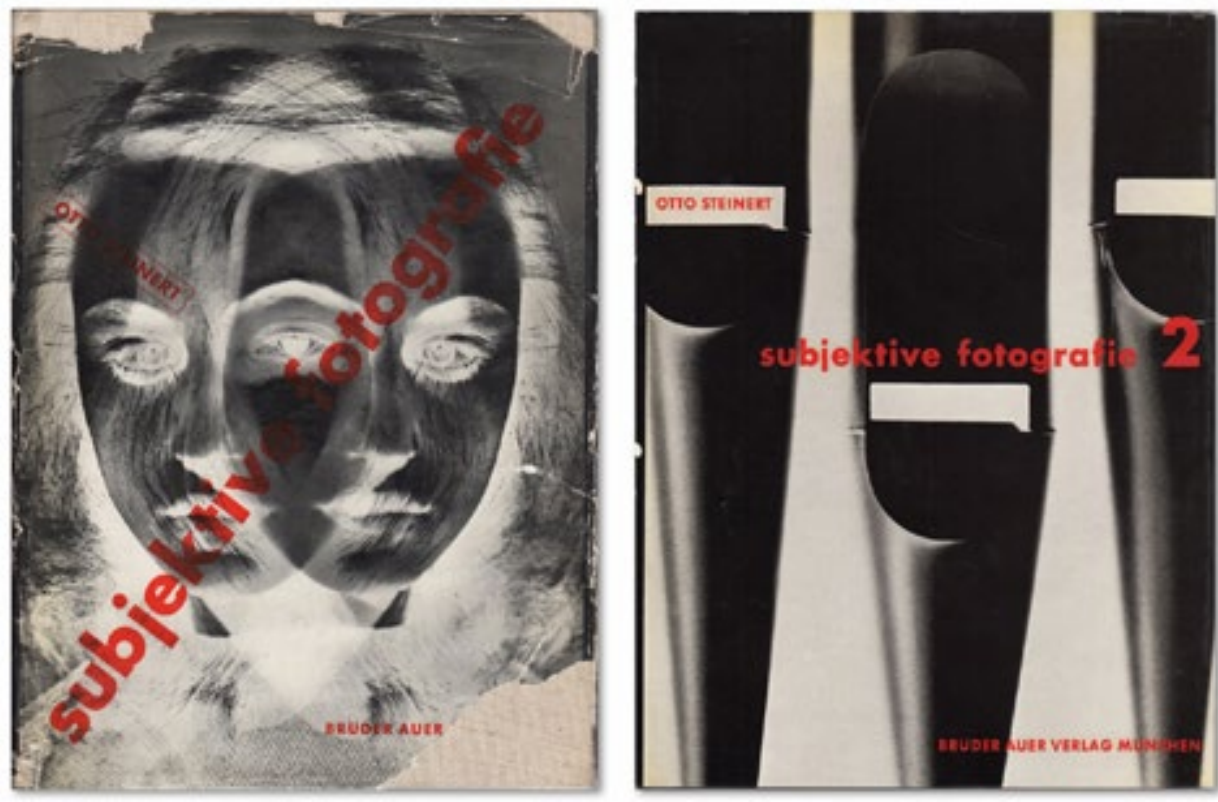

Figura 2. Libros subjektive fotografie (1952) y subjektive fotografie 2 (1958), de Otto Steinert

En 1954 se llevó a cabo una segunda exposición Fotografía subjetiva que luego se trasladó a París y a Japón. Al año siguiente se publicó el libro Fotografía subjetiva 2 [Figura 2] y en 1958 tuvo lugar la tercera y última exposición nuevamente en Photokina, con posteriores reposiciones en otras ciudades alemanas, en Bélgica y en Italia.

En búsqueda de visibilidad e intercambio internacional, los libros se publicaron en tres idiomas y las exposiciones, o partes de ellas, circularon, como se puede observar, por varios países. Estas participaciones en el extranjero junto a la difusión de Fotoform en diferentes medios gráficos llevaron el concepto de fotografía subjetiva de Steinert a toda una red de artistas en diversas partes del mundo. Puntualmente en América Latina, en 1955 se presentó la exposición Otto Steinert y sus alumnos en el Museo de Arte Moderno 
de San Pablo, Brasil, con el apoyo del Foto Cine-Club Bandeirante (FCCB). Esta institución publicó en su boletín una extensa nota sobre la exposición y los alcances de la fotografía subjetiva, ilustrada con algunas de las fotografías participantes e imágenes del evento. ${ }^{8}$ Previamente, en 1951, Steinert había enviado fotografías al 10. Salón Internacional de Arte Fotográfico de San Pablo patrocinado también por FCCB. ${ }^{9}$

Steinert ocupó un papel central a nivel mundial en la fotografía de posguerra y se constituyó como una personalidad notable cuyo trabajo y juicio eran respetados en diversos círculos, tanto por fotógrafos artísticos y experimentales como por fotógrafos profesionales (Berghmans, 2011). La fotografía subjetiva se conformó durante la década del cincuenta como un nuevo lenguaje fotográfico transnacional que, según afirma Valentin (2016), mientras dialogaba con los diversos movimientos de renovación en las artes, también buscaba la afirmación de su propio estatus artístico autónomo. Su influencia se expandió a otros rincones de Europa, como Bélgica, en donde el propio Steinert ayudó a organizar importantes exposiciones fotográficas locales (Berghmans, 2011), o España, en donde Fotoform y la fotografía subjetiva ejercieron una importante influencia en el grupo fotográfico Afal (Terré Alonso, 2016).

\section{Afal y La Carpeta de los Diez}

La Agrupación Fotográfica Almeriense (Afal) fue un colectivo de fotógrafos que inició un proceso de renovación fotográfica a mitad del siglo XX en España, durante el franquismo. Según afirma María Peralta Barrios (2018) la fotografía española de entonces, imposibilitada de la llegada de nuevas tendencias y movimientos fotográficos, se encontraba «anquilosada en el salonismo» (p.1) y en el pictorialismo, género constituido en el estilo fotográfico del régimen franquista, «una expresión artística concebida como algo meramente ceremonial al servicio del Estado» (p. 2). En este contexto, se creó en 1950 una asociación para la difusión y la renovación de la fotografía española tras la posguerra (Terré Alonso, 2016, p. 3). Si bien la agrupación comenzó en Almería, una de las zonas más aisladas y deprimidas de España en aquel momento, sus heterogéneos miembros, tanto fotógrafos amateurs como profesionales, se encontraban dispersos por toda la región española. ${ }^{10}$

Una de las principales producciones de Afal fue su revista homónima, la cual tuvo sus orígenes como un boletín interno de la agrupación. En 1955 fueron elegidos nuevos directivos, lo que significó un nuevo período para la agrupación que rompió con la

8 Ver Teixeira Scavone, R. (1955). Diagnostico do subjetivo [Diagnóstico de lo subjetivo]. Boletín Foto-Cine, 97, 8-13.

9 Para un estudio específico sobre la relación de la fotografía subjetiva y Otto Steinert con Brasil ver el artículo de Andreas Valentin (2016) citado previamente.

10 «En Afal se dio cita un grupo variado de fotógrafos documentalistas y subjetivistas que compartían un interés por la función social del fotógrafo y su implicación en la realidad de su tiempo [...]. Sus procedencias y ambiciones fueron bien distintas: fotógrafos amateurs como Gabriel Cualladó y Ricard Terré; algunos de ellos ligados a la cultura y las artes plásticas, como Gonzalo Juanes y Josep Maria Casademont y muchos que iniciaban su carrera profesional en la fotografía como Xavier Miserachs, Ramón Masats, Oriol Maspons y Julio Ubiña, entre otros» (Terré Alonso, 2016, p. 3). 
tradición pictorialista y buscó ofrecer nuevos planteamientos fotográficos inspirados en otras corrientes existentes en el extranjero (Peralta Barrios, 2018). Uno de sus objetivos fue realizar una revista abierta a formas fotográficas renovadas, que dio lugar en 1956 a una nueva etapa de apogeo de la revista Afal. Con un importante cambio cualitativo, Afal se convirtió en una revista con una línea editorial dirigida a la fotografía documental y humanista en la que existía una preocupación por la imagen como instrumento de cultura y comunicación. Este medio permitió que numerosos fotógrafos pudieran difundir sus fotos y darlas a conocer entre los aficionados a la fotografía, como así también difundir nuevos aspectos teóricos y diversos fotógrafos extranjeros, incluyendo en gran parte de sus números importantes textos de la literatura fotográfica de la época traducidos al español. Asimismo cada número contaba con un portfolio monográfico dedicado a un fotógrafo o a un grupo fotográfico (Terré Alonso, 2016). La revista abarcó otros espacios culturales como el cine o la poesía. Se publicaron en total 36 ejemplares, aunque de un modo discontinuo, hasta 1963, a pesar de la censura establecida sobre los medios gráficos durante aquellos años del franquismo y los diversos problemas económicos que atravesó en particular la publicación. ${ }^{11} \mathrm{Al}$ año siguiente la agrupación Afal cesó su actividad.

Según afirma la investigadora Laura Terré Alonso (2016), hija del miembro Ricard Terré, Afal se conformó como un grupo heterogéneo en el que tuvieron lugar distintos planteamientos fotográficos, pues no existía un estilo específico asumido por sus miembros. El nexo de unión entre ellos se basaba en el intercambio y en la confrontación de propuestas, que podían resultar tanto del acuerdo como de la disensión. Se trató así de un colectivo diverso en sus propuestas fotográficas, pero coincidente en el deseo de realizar una fotografía innovadora y diferente respecto a la que se realizaba en España en aquel momento.

Si bien primó en general, como principal referencia, la fotografía humanista francesa y norteamericana y el neorrealismo italiano, ${ }^{12}$ fue de gran importancia para muchos miembros del grupo la fotografía subjetiva. Las conexiones entre Steinert y Afal fueron varias y profundas. Por un lado, el primero promocionó la fotografía española en su última muestra de Subjektive fotografie [Fotografía Subjetiva], a partir de imágenes publicadas en el anuario que realizó la agrupación española en 1958. En 1961 Afal dedicó el N.ํ32 de su revista a Steinert, con varias notas alusivas a él. Se publicaron allí los artículos «Fotografía Subjetiva» firmada por el director de la revista José Artero García y «La obra de Otto Steinert por primera vez en España», ilustrada con 57 fotografías de su autoría, 12 de las cuales son a página completa. Asimismo se incluyó el texto de Steinert Sobre

11 Para un estudio detallado de la historia de la revista Afal y las negociaciones y estrategias utilizadas para sortear la censura establecida ver Historia del Grupo Fotográfico Afal: 1956/1963 (2006), de Laura Terré Alonso. 12 El neorrealismo italiano fue un movimiento principalmente cinematográfico que surgió en Italia a partir de 1945 con el objetivo de mostrar condiciones sociales auténticas. La fotografía italiana de entonces se inscribió también en este movimiento documental de descubrimiento y denuncia de las condiciones en las que se encontraba Italia durante aquellos años, en el marco de la modalidad de trabajo de reportajes para medios gráficos con el estilo de la revista norteamericana Life. Para un estudio puntual ver NeoRealismo. La nueva imagen de Italia 1936-1960 (2007), de Enrica Viganò. 
las posibilidades creadoras de la fotografía traducido al español (Steinert, 1961), citado previamente en este trabajo.

Algunos años después, durante 1962 y 1963, se realizó una exposición de Steinert itinerante por España, la cual contó con una nota especial en el N. ${ }^{\circ} 36$ de la revista Afal [Figura 3]. Según afirma Terré Alonso (2016), a partir de sus contactos con Steinert Afal defendió la fotografía abstracta como signo de modernidad, «la revista desde sus inicios emprendió una labor pedagógica para acercar el arte abstracto al público, cuya exposición y trabajo crítico tenía un auge inusitado en la España de 1950» (p. 7).

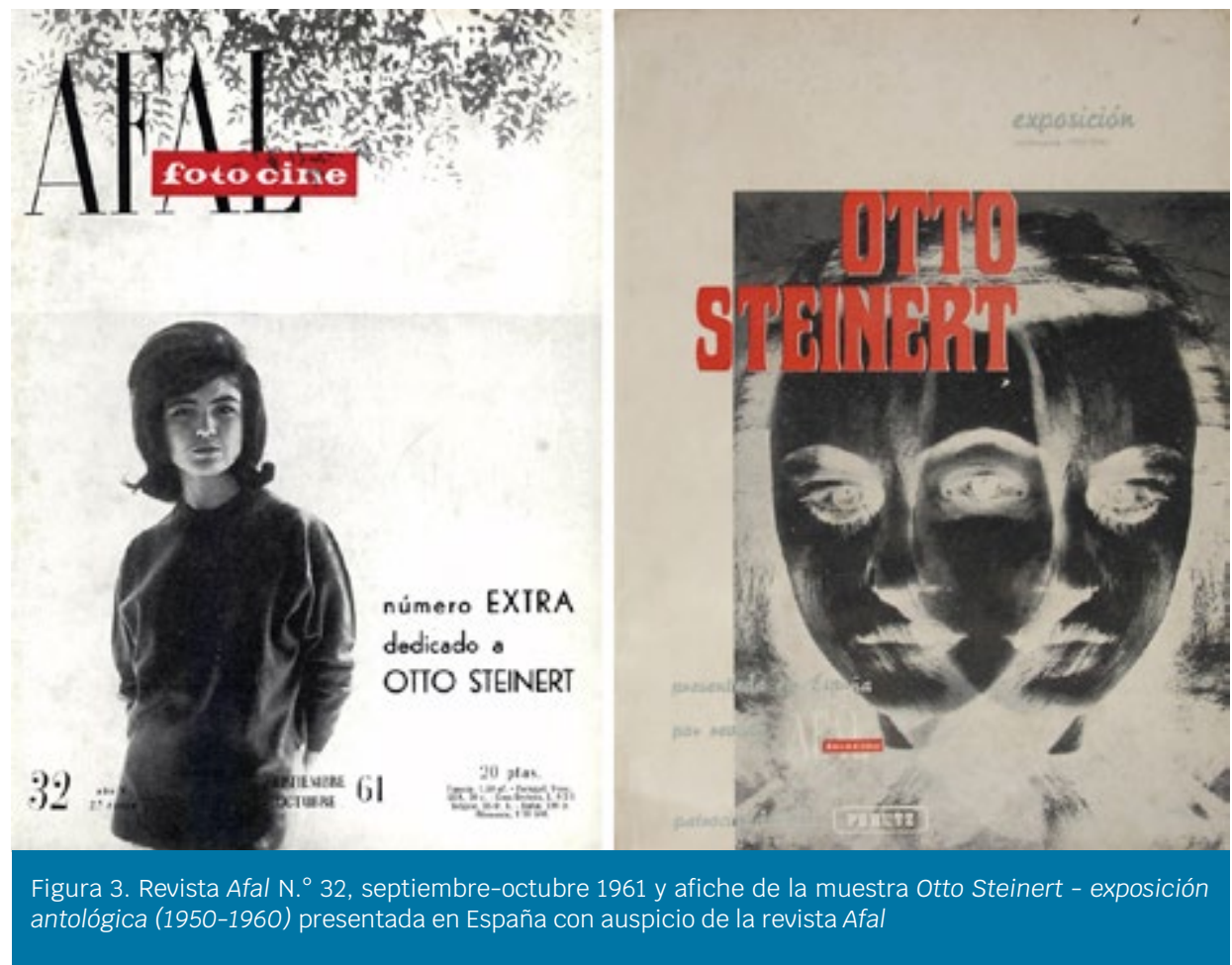

No obstante, la fotografía subjetiva como propuesta y como movimiento también despierta críticas. La doble influencia presente en Afal, la fotografía humanista y la fotografía subjetiva, es entendida por Jorge Ribalta (2007) como una "ambivalencia al cuadrado» (p. 86). Para el historiador español, la fotografía humanista es de por sí un movimiento de signo político ambivalente, porque si bien surge de una tradición revolucionaria se desplaza tras la guerra a un proceso de integración en la socialdemocracia y visualiza la incorporación de las clases populares al capitalismo de la posguerra. Pero además, Ribalta (2007) caracteriza a la fotografía subjetiva de estar «ambiguamente lastrada por el legado nacionalsocialista» (p.86) y contrarresta, así, la influencia del programa del realismo humanista con un discurso formalista sobre la abstracción. «La dialéctica o ambivalencia 
entre realismo y formalismo, tanto de la Subjektive Fotografie como de Afal, podrían verse como vinculados a los legados del fascismo, a diferencia de los realismos de izquierda italiano y francés» (Ribalta, 2007, p. 86), afirma el autor. Sin embargo, para Terré Alonso (2016) el gran mérito de Afal fue la introducción de sus fotógrafos en certámenes y en muestras colectivas en el extranjero, ${ }^{13}$ como así también el acercar al ámbito fotográfico español de entonces las nuevas corrientes y propuestas fotográficas que sucedían en otros países.

Esta doble influencia humanista y subjetiva puede encontrarse también, del otro lado del océano pero durante los mismos años, en el grupo fotográfico argentino La Carpeta de los Diez. Con sede en Buenos Aires, entre 1952 y 1959, se trató de un grupo por el cual pasaron un total de 14 fotógrafos de diversas nacionalidades. ${ }^{14} \mathrm{El}$ nombre del mismo responde a su particular metodología de trabajo, llevada a cabo a través de carpetas temáticas con fotografías y con hojas en blanco en las que cada miembro plasmaba su opinión sobre las tomas incluidas por los demás.

Los miembros de La Carpeta tenían en común el ser todos fotógrafos profesionales en diversas áreas de la fotografía y el contar todos con una importante trayectoria previa. El grupo reunió fotógrafos de prensa como Juan Di Sandro - quien fuera fotógrafo de La Nación durante sesenta años- o fotógrafos retratistas de estudio, como Annemarie Heinrich —especializada en fotografía de celebridades y artistas-, junto con fotógrafos documentalistas como Hans Mann, quien venía recorriendo la Argentina relevando su patrimonio cultural para la Academia Nacional de Bellas Artes. De este modo, las producciones del grupo como tal no eran homogéneas, ya que cada miembro mostraba lo mejor dentro su área de trabajo. El objetivo final de La Carpeta era la conformación de un espacio de discusión e intercambio entre fotógrafos experimentados y profesionales, en donde pudiesen debatir nuevas propuestas en torno a la fotografía, compartir materiales de estudio y dar a conocer sus producciones.

La búsqueda renovadora de los miembros de La Carpeta de los Diez se vio técnicamente reflejada en la exploración de nuevos recursos y temáticas mediante el uso de diversas técnicas de manipulación de las fotografías, como fotomontajes, collages y solarizaciones, como así también encuadres poco convencionales y múltiples exposiciones al momento de la toma. Muchas veces estos recursos se utilizaban de manera complementaria, por ejemplo en tomas realizadas en estudio posteriormente solarizadas o utilizadas para la realización de montajes. Observando el tipo de imágenes que los miembros de La Carpeta

13 Entre las que destacan la participación en el Salon Albert I de Charleroi (Bélgica) y en la Bienal de Pescara (Italia) en 1958; la exposición colectiva en París en 1959 junto con el Club Photographique Les 30 × 40, que itineró por Berlín, Moscú y Milán; y la inclusión que hizo Edward Steichen de varias fotografías del Anuario de la Fotografía Española de 1958 en una exposición en el MoMA en 1959 (Terré Alonso, 2016).

14 En 1953 comenzaron siendo 10 miembros, pero con el correr de los años fueron saliendo algunos y entrando otros fotógrafos nuevos. Pasaron en total por el grupo Pinélides Fusco, Eduardo Colombo de Argentina; Max Jacoby, Annemarie Heinrich, Hans Mann e Ilse Meyer de Alamania; Juan Di Sandro y Giuseppe Malandrino nacidos en Italia; George Friedman y Alex Klein de Hungría; Anatole Saderman de Rusia, Fred Schiffer de Austria, Boleslaw Senderowicz nacido en Polonia y Augusto Valmitjana de España. 
generaban, podemos afirmar que en el grupo coexistían también influencias tanto de la fotografía humanista, representada por fotógrafos documentalistas como Eduardo Colombo (Facio, 1995), como de la fotografía subjetiva, siendo más importante la relación con esta última. Primeramente se debe destacar que, durante todos los años de existencia del grupo, más de la mitad de sus miembros habían llegado desde Europa. Gran parte sus fotógrafos habían nacido puntualmente en Alemania o hablaban alemán, específicamente Annemarie Heinrich, Hans Mann, Ilse Mayer, Max Jacoby, Alex Klein, Fred Schiffer y Antaole Saderman. Juan Travnik (2004) afirma que el movimiento comenzado por Steinert tuvo una fuerte repercusión en Heinrich, quien en 1954 realizó un viaje de formación y perfeccionamiento a Alemania en el cual "conoció personalmente a Otto Steinert, con quien tomó unas pocas clases y mantuvo algunas entrevistas en Colonia» (p. 25). ${ }^{15}$

Uno de los objetivos de La Carpeta fue la realización de exposiciones anuales en las cuales cada miembro mostraba cierto número de fotografías seleccionadas según criterios establecidos año a año. Puntualmente en la exposición de 1956, con lugar en el Salón Siam, se exhibieron cinco fotografías de cada autor junto a dos conjuntos grupales temáticos de imágenes, uno de los cuales estaba dedicado a la fotografía subjetiva. Annemarie Heinrich registró fotográficamente dicha exposición y gracias a unas de sus fotos podemos conocer las imágenes que conformaron ese panel [Figura 4]. Luego de un estudio puntual de los acervos de los miembros del grupo, fue posible identificar la autoría de cuatro de las siete fotos allí incluidas. Comenzando por la fila superior, de izquierda a derecha las fotos reconocidas son de George Friedman, Eduardo Colombo, Anatole Saderman y de un autor no reconocido. Las fotos de la fila inferior de izquierda a derecha son de autores no reconocidos, salvo la última que es de Annemarie Heinrich. Las tres fotografías que no pudieron ser identificadas pertenecen a Alex Klein, Fred Schiffer y Juan Di Sandro, aunque no pudo determinarse a quién corresponde cada una.

En una nota publicada en la revista Correo Fotográfico Sudamericano (Del Conte, 1956) se describe el conjunto expuesto por cada autor y se realizan duras críticas compositivas y temáticas, pero se alaba la calidad del trabajo de todos. La nota afirma que el conjunto presentado bajo el rótulo de fotografía subjetiva «lleva a pensar sobre el significado de esa denominación y si se han puesto de acuerdo los expositores al respecto». Según una de las definiciones que allí se enuncia, se entendería por fotografía subjetiva:

Aquella búsqueda que evita deliberadamente las imágenes comunes a la visión humana, intenta expresar con mayor libertad el espíritu del autor mediante efectos desacostumbrados que no rememoren tan de cerca el documento objetivo; se vale para ello de recursos técnicos o de composición (Del Conte, 1956, pp.24-25).

15 En aquel viaje realizó un curso de fotografía color con las técnicas de Agfa en la escuela de Hermann Hartz, en la ciudad de Hüchst, y participó de un seminario de fotografía de grupos en la escuela de Marta Hüpfner, en Frankfurt (Travnik, 2004, p. 25). 


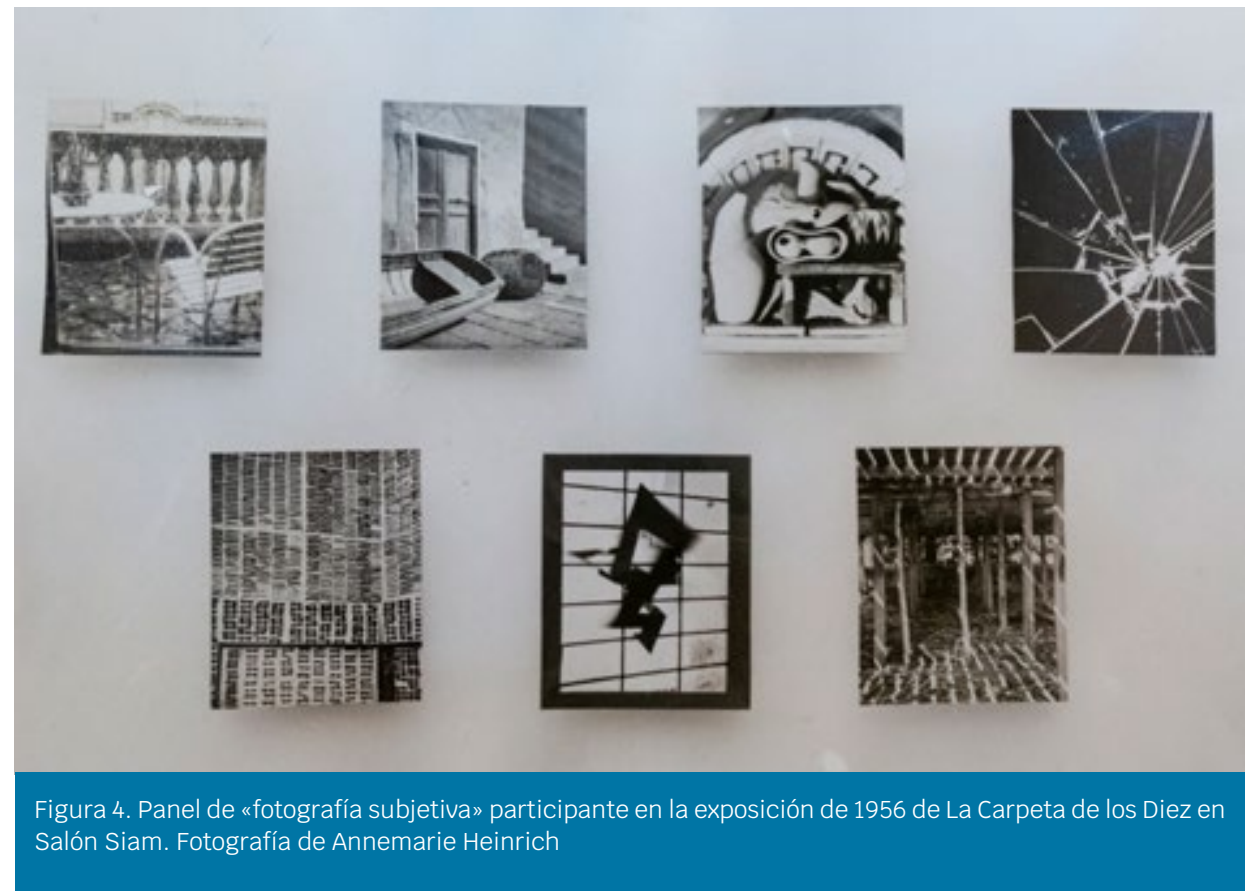

Bajo esta definición de fotografía subjetiva se critica la incorporación a dicho conjunto de las fotografías de Friedman, Colombo, Di Sandro y Heinrich por presentar «un tratamiento absolutamente clásico» (Del Conte, 1956, pp.24-25). Sin embargo, la misma nota afirma que «el rótulo de subjetivo podría aplicarse a todas las obras expuestas por [Alex] Klein en el salón». Si bien no fue posible determinar cuáles son las fotos de Klein y Di Sandro, sí se reconocieron las imágenes pertenecientes a los otros tres autores nombrados, las cuales corresponden justamente a las fotografías más figurativas, realizadas con un mayor ángulo de cobertura que nos permite identificar los espacios en las que fueron obtenidas. Como se puede apreciar, Friedman participó con la vista de un balcón un día de lluvia a través de un vidrio; Colombo eligió una foto que retrata el juego de líneas, texturas y luces de una escalera, una vieja puerta y parte de un bote a pleno mediodía; por su parte, Heinrich participó en el panel con una foto del entramado de líneas, luces y sombras de lo que pareciera ser una estructura de madera sobre la arena. Si sometemos a dichas imágenes a los «factores técnicos y subjetivos efectivos» que propuso Steinert (1961, p.33) para determinar qué fotografías pueden considerarse subjetivas, la afirmación de Del Conte (1956) podría tomarse como acertada. Sin embargo, el movimiento de la fotografía subjetiva era muy amplio y permitía albergar este tipo de fotos, sin atenerse estrictamente a las primeras clasificaciones de Steinert.

El surgimiento de Fotoform y los postulados de la fotografía subjetiva venían teniendo eco en las publicaciones especializadas argentinas. En septiembre de 1950 Correo Fotográfico Sudamericano ilustró la tapa y varias notas de su N. ${ }^{\circ} 643$ con fotos de autores pertenecientes al grupo alemán. Su director de entonces, Alejandro Del Conte, expuso los principales 
lineamientos de Fotoform en una nota titulada «Grupos», afirmando que «no hace ningún favor al arte fotográfico latinoamericano la ausencia de grupos que, independientemente de la rutina de los fotoclubes, definan, propicien y difundan una tendencia artística cualquiera» (Del Conte, 1950, pp. 22-38). Del Conte indicaba que la propuesta de Fotoform era provocadora ya que planteaba al observador una serie de incógnitas sobre las obras mediante las cuales los autores se proponían «revolucionar el ambiente» (Del Conte, 1950, p. 22). Esta búsqueda de interrogantes y el corrimiento de la fotografía más allá del simple reflejo de la realidad permitía desafiar los usos y alcances del medio, «la obra común, por bella que sea no provoca esas consecuencias y no "trabaja” para la fotografía» (Del Conte, 1950, pp. 22-38).

Por su parte, la revista Fotocámara publicó en marzo de 1952 el artículo «Nuevas tendencias ante la ortodoxia fotográfica» firmado por Franz Roh, historiador nombrado anteriormente como un aval importante para la fotografía subjetiva propuesta por Steinert. Como afirma Carlos Fernández (2015), la revista no incorpora ninguna explicación o comentario extra sobre el artículo, ni se indica el origen del mismo. Roh (1952) desarrolla allí su concepto sobre las posibilidades de la fotografía frente a la reproducción del mundo circundante, afirmando que «al lado de este extenso panorama de la fotografía, que se podría denominar objetivo, hay un sector subjetivo, con el cual se penetra en los ámbitos del arte» (Roh, 1952, pp. 20-22). ${ }^{16}$ Años más tarde, en 1957, Fotocámara publicó también el artículo «A propósito de los salones» de Steinert, en el cual el fotógrafo, docente y asiduo organizador de exposiciones realiza una crítica al formato de los salones internacionales de arte fotográfico que parecieran repetirse del mismo modo y con la misma dinámica en todas las ciudades del mundo.

La publicación de artículos con relación a las nuevas tendencias en fotografía y, particularmente, sobre fotografía abstracta, subjetiva o moderna, continuó en las revistas especializadas de entonces durante los siguientes años. Por ejemplo, Correo Fotográfico Sudamericano publicó en 1953 un artículo llamado «Una nueva tendencia estética. Fotografía abstracta», firmado por Ada Nelly de Cristófaro, ilustrado con fotografías de Heinz Hajek-Halke, miembro de Fotoform, junto a imágenes de otros fotógrafo alemanes. En él se habla de las «modernas concepciones artístico-fotográficas» y se propone el lema «la fotografía es sinónimo de la realidad, como de la irrealidad creada por el artista» (de Cristófaro, 1953, pp. 18-19), a la vez que se utilizan los términos fotografía abstracta y fotografía subjetiva indistintamente. En este contexto, no fueron solo los fotógrafos de La Carpeta quienes se hicieron eco en la Argentina de las búsquedas formales y conceptuales que se proponían desde otras latitudes; podemos nombrar sin dudas a muchos otros fotógrafos coetáneos, como los miembros del grupo Fórum, con Sameer Makarius a la cabeza. ${ }^{17}$

16 Al artículo «Nuevas tendencias ante la ortodoxia fotográfica» (1952), de Franz Roh solo se pudo tener acceso a través del artículo «Fotografía artística en la Argentina 1950-1960» (2015), de Carlos Alberto Fernández.

17 En 1956 Makarius conformó junto a otros fotógrafos el grupo Fórum, con declaradas influencias de la fotografía subjetiva. Algunas fotografías suyas fueron incluidas en las exposiciones de la galería Kicken de Berlín Subjektive fotografie, Adventures in the visual field [Fotografía subjetiva, aventuras en el campo visual] en 2013 y Subjektive Fotografie 2: More Adventures in the Visual Field [Subjektive Fotografie 2: más aventuras en el campo visual] en 2014. 
Para comprender tanto la producción fotográfica de un grupo en particular como de todo un período en general, no basta con abordar únicamente sus imágenes. Las publicaciones especializadas, los registros de exposiciones, los viajes de estudio y los diversos documentos relacionados con las actividades de discusión y de creación nos permiten, en los casos aquí trabajados, identificar conexiones y ahondar en los lazos construidos durante la década del cincuenta para proponer nuevos entrecruzamientos entre las dinámicas y producciones transatlánticas. Según lo expuesto hasta el momento, y siguiendo a Valentin (2016), la fotografía que surgió durante esta década tuvo la firma de toda una época, con adaptaciones locales según las características y procesos de cada región o país. En Alemania fue una respuesta a una situación específica de posguerra, que incorporó el espíritu de reconstrucción así como la «necesidad de encontrar una teoría fotográfica y un lenguaje visual que sean apropiados para su época pero también sin compromiso político» (Stiegler, 2006, p. 245). En otras regiones de Europa, como Bélgica y en España, aunque con ciertas diferencias coyunturales, este período sentó las bases de la institucionalización y reconocimiento de la fotografía como arte e inició, de esta manera, un proceso de sensibilización que ofreció a las posteriores generaciones de fotógrafos la oportunidad de desarrollar aspiraciones artísticas (Berghmans, 2011).

Dicha institucionalización y reconocimiento de la fotografía como arte puede ser extendido a los procesos ocurridos en la misma década dentro del ámbito fotográfico en Brasil y Argentina, aunque de este lado del mundo no estuvo necesariamente ligado al mismo sentido reconstructivo de posguerra. En el caso argentino, La Carpeta de los Diez buscó desarrollar una práctica fotográfica de corte artístico, llevada a cabo por fotógrafos profesionales e independiente de los fotoclubes. Sus miembros retomaron elementos de la corriente subjetiva, entre otras, para generar prácticas y dinámicas propias en un ámbito de creación que había comenzado a especializarse y diversificarse. Indagar en las corrientes que los fotógrafos miembros del grupo observaban y restablecer los lazos que los unió con otros grupos y espacios fotográficos de diferentes países permite ahondar en el panorama general de la fotografía de los años cincuenta en Argentina y problematizar cómo fue el establecimiento de un medio complejizado y relacionado cada vez más con el circuito artístico.

\section{Referencias}

Baker, S. (2018). 1940-1960 Photography's Sense of Abstraction [1940-1960 El sentido de la abstracción de la fotografía]. En Shape of Light. 100 Years of Photography and Abstract Art [La forma de la luz. 100 años de fotografía y arte abstracto] (pp. 87-135). Londres, Inglaterra: Tate Modern.

Berghmans, T. (2011). The emergence of photography as an art form in Belgium, 1950-1965 [El surgimiento de la fotografía como una forma de arte en Bélgica, 1950-1965]. Depth of Field, 1(1). Recuperado de https://depthoffield.universiteitleiden.nl/0101a02/

Cristófaro, A. N. (1953). Una nueva tendencia estética. Fotografía abstracta. Correo Fotográfico Sudamericano, 702, 18-19. 
Del Conte, A. (1950). Grupos. Correo Fotográfico Sudamericano, 643, 22-38.

Del Conte, E. (1956). El salón de 'Los Diez’. Correo Fotográfico Sudamericano, 788, 24-25.

Facio, S. (1995). La fotografía en la Argentina. Desde 1840 a nuestros días. Ciudad Autónoma de Buenos Aires, Argentina: La Azotea.

Fernández, C. A. (2015). Fotografía artística en la Argentina 1950-1960. Actas de Diseño, 10 (19), 165-172.

Gernsheim, H. y Gernshaw, A. (1965). A concise history of Photography [Una breve historia de la fotografía]. Londres, Inglaterra: Thames and Hudson.

Guillemot, M. (2001). Dictionnaire mundial de la photographie [Diccionario mundial de la fotografía]. Montreal, Canadá: Larousse.

Peralta Barrios, M. (2018). El grupo Afal. Un conjunto de individualidades. Ponencia presentada en el Congreso Internacional de Cultura Visual. Pontificia Università della Santa Croce, Roma, Italia.

Ribalta, J. (2007). Afal como síntoma. La ambivalencia de la vanguardia fotográfica española. Revista El viejo Topo, 228, 79-87.

Ribalta, J. (2008). Archivo universal. La condición del documento y la utopía fotográfica moderna. Barcelona, España: Museu d'Art Contemporani de Barcelona.

Ribalta, J. (2009). Espacios fotográficos públicos. Exposiciones de propaganda, de Pressa a The Family of Man, 1928-1955. Barcelona, España: Museu d'Art Contemporani de Barcelona.

Roh, F. (1952). Nuevas tendencias ante la ortodoxia fotográfica. Fotocámara, 85, 40-42.

Steinert, O. (1957). A propósito de los salones. Fotocámara, 108, 56-57, 86-88.

Steinert, O. (1961). Sobre las posibilidades creadoras de la fotografía. Afal fotocine, 32, 28-34.

Stiegler, B. (2006). Theoriegeschichte der Photographie [Historia de la teoría de la fotografía]. Múnich, Alemania: Bild und Text.

Teixeira Scavone, R. (1955). Diagnostico do subjetivo [Diagnóstico de lo subjetivo]. Boletín FotoCine, 97, 8-13.

Terré Alonso, L. (2006). Historia del Grupo Fotográfico Afal: 1956/1963. Madrid, España: PhotoVision. 
Terré Alonso, L. (2016). El grupo fotográfico Afal (1956-1963) [Catálogo de exposición]. Madrid, España: Museo Nacional Centro de Arte Reina Sofía.

Travnik, J. (2004). Annemarie Heinrich. Un cuerpo, una luz, un reflejo. Ciudad Autónoma de Buenos Aires, Argentina: Larivière.

Valentin, A. (2016). Light and Form: Brazilian and German Photography in the 1950s [Luz y forma: fotografía brasileña y alemana en la década de 1950]. Konsthistorisk tidskrift/ Journal of Art History, 85(2). doi: 10.1080/00233609.2015.1136354

Viganò, E. (2007). NeoRealismo. La nueva imagen de Italia 1936-1960. Madrid, España: La Fábrica. 